\title{
Oxidação do aço inoxidável ferrítico AISI 409 em altas temperaturas em atmosfera de ar sintético
} High temperature oxidation of ferritic stainless steel AISI 409 in atmosphere synthetic air

Ediomar C. Serra ${ }^{1,2}$, Ayrton de S. Brandim², Givanilson B. de Oliveira ${ }^{1}$, Maria de F. Salgado ${ }^{1,2}$

\section{RESUMO}

Esta pesquisa trata da investigação da cinética de crescimento e a composição dos filmes de óxidos formados sobre o aço inoxidável ferrítico AISI 409 entre as temperaturas $850^{\circ} \mathrm{C}$ e $950^{\circ} \mathrm{C}$, na atmosfera de ar sintético contendo $20 \%$ de $\mathrm{O}_{2}$. As amostras foram oxidadas em um forno tubular durante 2 h. A cinética de oxidação, foi estabelecida medindo-se o ganho de massa por unidade de área versus tempo. A microestrutura e a composição química dos óxidos foram analisadas por microscopia eletrônica de varredura e espectroscopia de energia dispersiva EDS. Análises químicas descrevem que o elemento químico majoritário a $850^{\circ} \mathrm{C}$ é cromo no filme formado, nas outras temperaturas predomina Fe. Outros elementos de liga como titânio e o silício são encontrados em pequenas quantidades até $900^{\circ} \mathrm{C}$. Ao se comparar as taxas de oxidação, verificou-se que o aço 409 ganhou massa em ordem crescente de temperatura.

Palavras-chaves: Temperatura, Oxidação em ar; Filmes.

\section{ABSTRACT}

This research is investigating the kinetics of growth and composition of the oxide films formed on the ferritic stainless stee AISI 409 between temperatures $850^{\circ} \mathrm{C}$ and $950^{\circ} \mathrm{C}$ in synthetic air atmosphere containing $20 \%$ of $\mathrm{O}_{2}$. The samples were oxidized in a tube furnace for $2 \mathrm{~h}$. The kinetics of oxidation was established by measuring the mass gain per unit area versus time. The microstructure and chemical composition of the oxides were analyzed by scanning electron microscopy and energy dispersive spectroscopy EDS. Chemical analysis describe that the majority chemical element in $850^{\circ} \mathrm{C}$ is chromium formed in the film on the other temperatures that $\mathrm{Fe}$ is predominant. Other alloying elements such as silicon and titanium are found in small amounts up to $900^{\circ} \mathrm{C}$. When comparing rates of oxidation, it was found that the 409 steel has gained mass in order of increasing temperature.

Keywords: Temperature, Oxidation in air; Films.

1 Universidade Estadual do Maranhão (UEMA) - Caxias (MA), Brasil.

${ }^{2}$ Instituto Federal de Educação, Ciência e Tecnologia (IFPI) - Teresina (PI), Brasil.

Endereço para correspondência: Ediomar C. Serra - Rua Teófilo Dias, 1508 - CEP: 65600-090 - Caxias (MA), Brasil. 


\section{INTRODUÇÃO}

Aços inoxidáveis são ligas de ferro e cromo em sua composição química básica. São utilizados em diversos setores industriais e tecnológicos, devido a suas propriedades físicas e químicas, especialmente a anticorrosiva ${ }^{(1,2)}$. Os aços inoxidáveis, sob pressão e temperatura normais levam muito tempo para sofrer corrosão, mas quando submetidos a altas temperaturas em ambientes com gases agressivos mesmo sob baixa pressão o processo de oxidação é acelerado. Uma atmosfera específica pode afetar não somente a cinética de oxidação, mas também a composição e propriedades físico - químicas dos filmes de óxidos formados sobre a superfície do aço em uso. A atmosfera natural (1atm) é oxidante, mas de baixa temperatura, nos escapamentos automotivos em funcionamento a temperatura é elevada, mas a quantidade de oxigênio é pequena já nos interconectores em células de combustíveis de óxido sólido as pressões parciais de oxigênio podem ser extremas ${ }^{(3,4)}$. Em todos esses meios os aço inoxidáveis estão sujeitos a corrosão. Dentre eles cita-se o ferrítico AISI 409, muito usado em conversores catalíticos e escapamentos automotivos ${ }^{(5)}$.

Dependendo do meio, os aços inoxidáveis são suscetíveis a corrosão intergranular, causado pelo empobrecimento em cromo das regiões adjacentes aos contornos de grãos, esse fenômeno ocorre quando o aço atinge a temperatura de sensitização ${ }^{(6,7)}$. Por razões como essa é importante, conhecer o comportamento de oxidação dos aços inoxidáveis ferríticos em altas temperaturas, em diferentes pressões parciais de oxigênio. Neste trabalho é apresentado o estudo da cinética de crescimento, micrografia e a composição química dos filmes de óxidos formados sobre o aço inoxidável ferrítico AISI 409 entre as temperaturas $850^{\circ} \mathrm{C}$ e $950^{\circ} \mathrm{C}$ durante 2 horas, na atmosfera de ar sintético, contendo $20 \%$ de gás oxigênio.

\section{MÉTODOS E MATERIAIS}

As amostras do aço inoxidável ferrítico AISI 409 utilizadas nesta pesquisa, foram cortadas, nas dimensões $(10 \times 10 \times 0,6) \mathrm{mm}$, lixadas nas duas superfície com lixas de carbeto de silício de granas adequadas, polidas com pastas de diamante de granulometrias de 3 e $1 \mu \mathrm{m}$. Sua composição química está descrita na Tabela 1 .

Após limpeza com acetona em ultrassom, suas massas foram mediadas em uma balança de sensibilidade de $\pm 0,0001 \mathrm{~g}$ e submetidas ao tratamento de oxidação isotérmico em Forno Tubular JUNG com controle de temperatura. Foi utilizado um tubo de sílica para inserir as amostras no forno, por um período de 2 horas de exposição, entre $850^{\circ} \mathrm{C}$ e $950^{\circ} \mathrm{C}$ em atmosfera de ar sintético. A cinética de crescimento dos filmes de óxidos formados sobre o aço foi determinada pela medida do ganho de massa por unidade de área versus tempo de oxidação. A caracterização microestrutural dos filmes de óxidos foi realizada por microscopia eletrônica de varredura MEV. A análise da composição química dos filmes de óxidos se fez por espectroscopia de energia dispersiva (EDS) e por Difração de Raios X com ângulo de incidência rasante.

\section{RESULTADOS E DISCUSSÃO Cinética de Oxidação}

A cinética de oxidação do aço AISI 409 em atmosfera de ar sintético durante $2 \mathrm{~h}$, entre as temperaturas de $850^{\circ} \mathrm{C}$ a $950^{\circ} \mathrm{C}$ está descrita na Fig. 1. Observa-se que a $850^{\circ} \mathrm{C}$ o aço apresenta ganho de massa por unidade de área inferior que nas outras temperaturas, assim como a $900^{\circ} \mathrm{C}$, oferece maior resistência a oxidação que $950^{\circ} \mathrm{C}$. O ganho massa por unidade de área em todas as temperaturas é decorrente da reação entre o oxigênio da atmosfera é os elementos de liga que possuem afinidade com ele, esse fenômeno requer a formação de um filme de óxido que inicialmente pode ser protetor, como é o caso de óxido de cromo que é o único óxido que se forma dessa liga com essa característica ${ }^{(4)}$.

A formação do filme de óxido formado sobre o aço 409 obedece a uma relação matemática parabólica, de forma que a cinética de oxidação ocorre por meio da difusão de oxigênio e/ou cátions através do filme $e^{(4,5)}$.

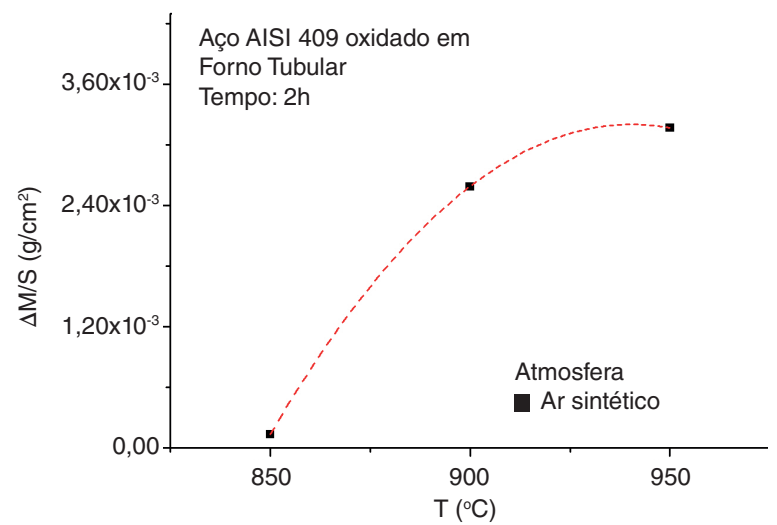

Figura 1: Cinética de oxidação do aço AISI 409 a $850^{\circ} \mathrm{C}, 900^{\circ} \mathrm{C}$ e $950^{\circ} \mathrm{C}$.

\section{Microestrutura e composição química da escama de óxido}

A micrografia e análise química do óxido formado sobre o aço 409 entre $850^{\circ} \mathrm{C}$ e $950^{\circ} \mathrm{C}$ na atmosfera ar sintético estão descritas nas Figs. 2 a 4 . Na Fig. 2 , a $850^{\circ} \mathrm{C}$, a microestrutura do filme apresenta características de corrosão preferencial nos contornos de grãos, em algumas regiões mais do que em outras. A análise EDS, indica o cromo como elemento predominante no filme formado sobre o aço, em proporções que pode-se considerar o referido filme como um óxido com característica protetora do tipo $\mathrm{Cr}_{2} \mathrm{O}_{3}$. Também, observa-se uma quantidade significativa de ferro, que pode ser proveniente do substrato do metal base devido à fina camada de óxido formada sobre o aço 409. Outros elementos como o $\mathrm{Ti}, \mathrm{Si}$ e Mn foram encontrados em menor quantidade.

Tabela 1: Composição química do aço AISI 409.

\begin{tabular}{|c|c|c|c|c|c|c|c|c|}
\hline AISI & C (\%) & Mn (\%) & SI (\%) & Cr (\%) & P (\%) & S (\%) & Ti (\%) \\
\hline 409 & 0,03 & 1,00 & 1,00 & 11,7 & 0,04 & 0,02 & Ti=6x (C+N) Min ou 0,70 Mx \\
\hline
\end{tabular}



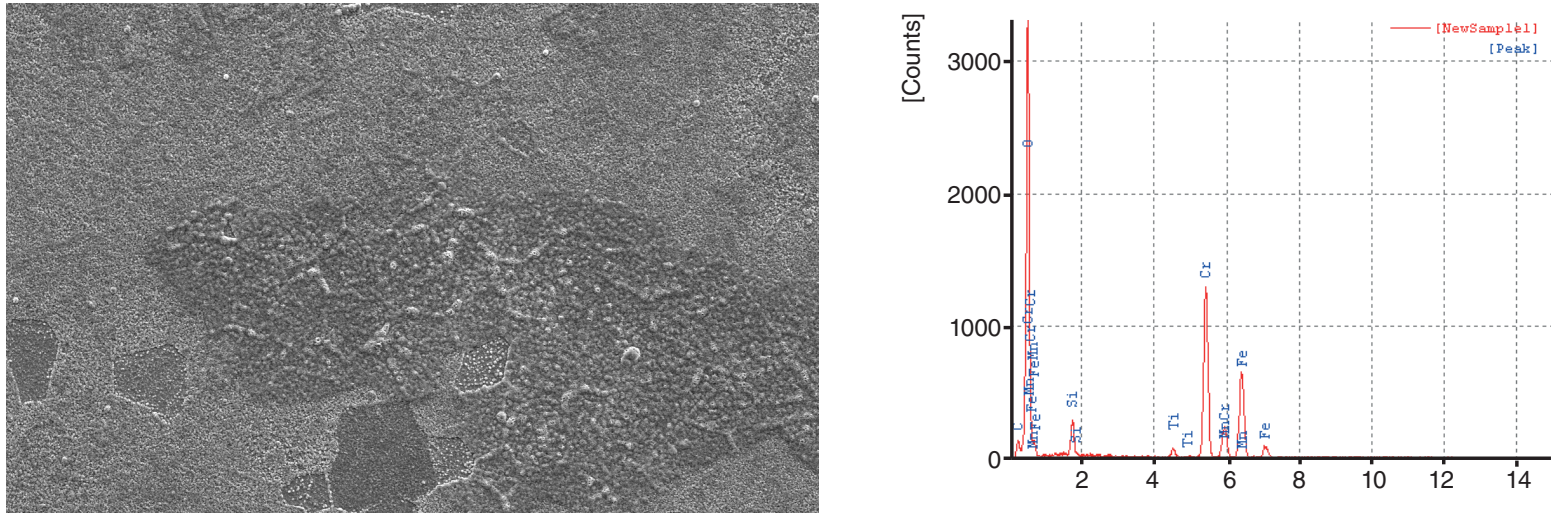

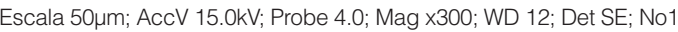

Figura 2: Microestrutura e EDS do filme de óxido formado sobre o aço AISI 409 a $850^{\circ} \mathrm{C}$.
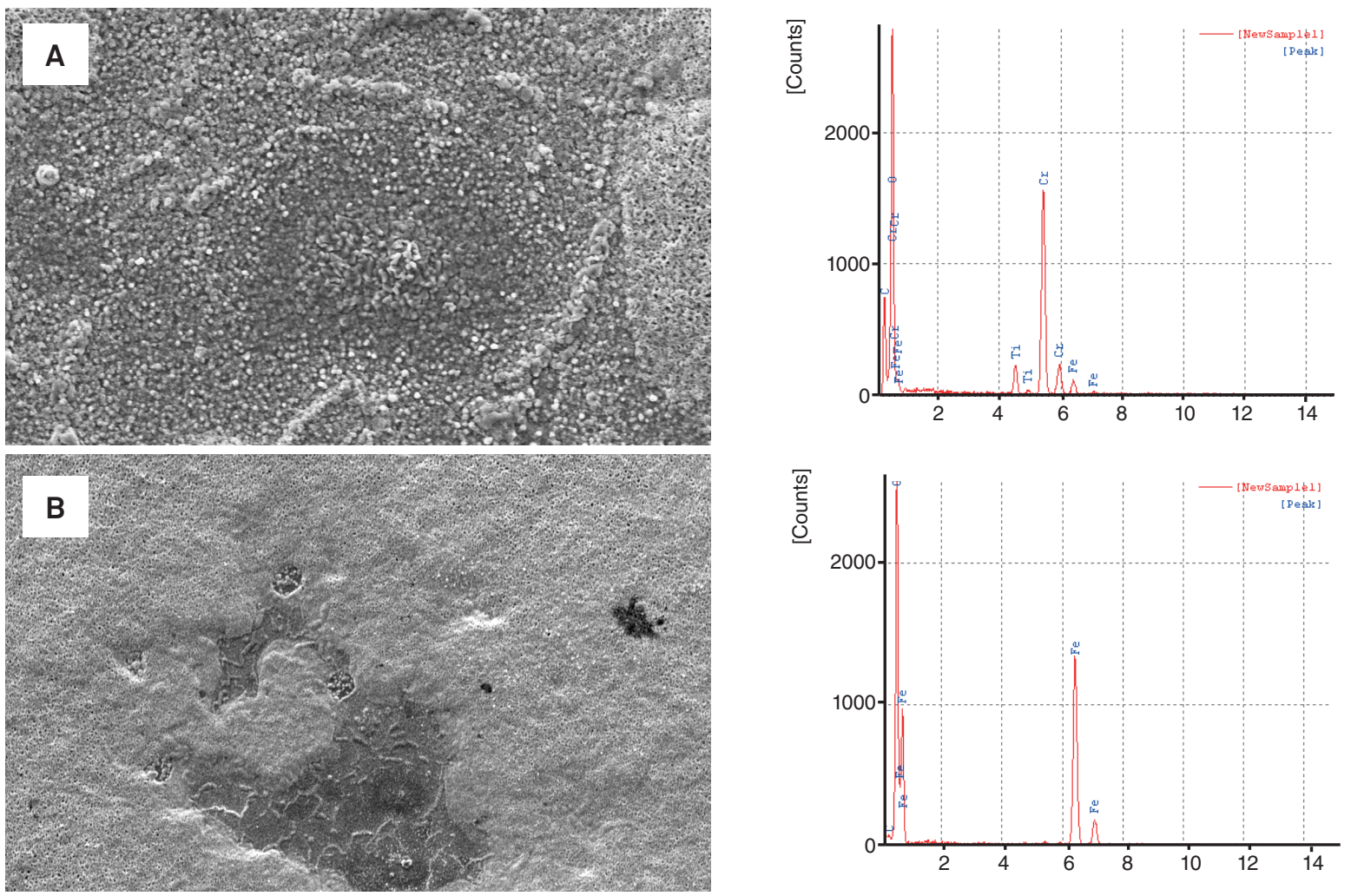

$[\mathrm{KeV}]$

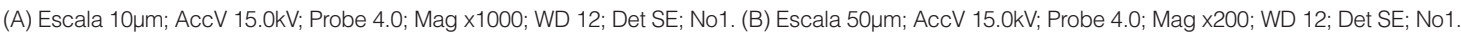

Figura 3: Microestrutura e EDS do filme de óxido formado sobre o aço AISI 409 a $900^{\circ} \mathrm{C}$.
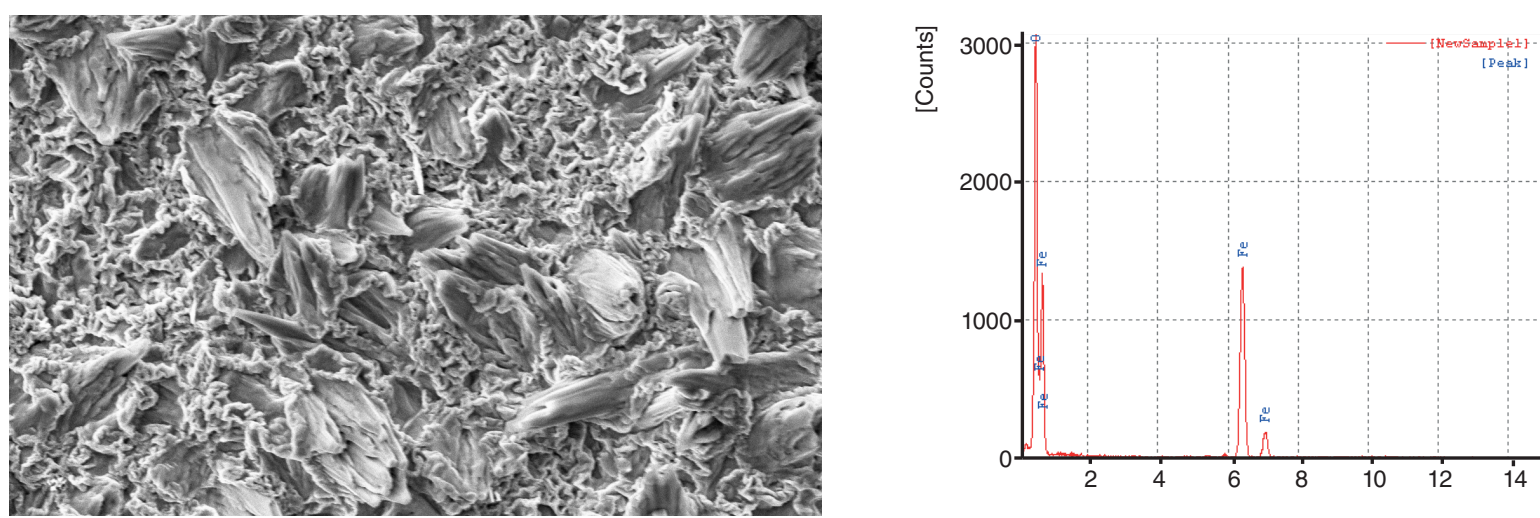

$[\mathrm{KeV}]$

Escala 10um; AccV 15.0kV; Probe 4.0; Mag x1000; WD 12; Det SE; No1

Figura 4: Microestrutura e EDS do filme de óxido formado sobre o aço AISI 409 a $950^{\circ} \mathrm{C}$. 
A $900^{\circ} \mathrm{C}$, a micrografia descreve que na região de interface ou região mais baixa, na qual formou-se óxido de cromo em grande quantidade e pouco ferro, Fig. 3 (A e B), indicando que o cromo pode ter migrado para uma pequena região e óxido de ferro cobriu todo o restante da superfície. Isto significa que o aço a essa temperatura não está protegido do fenômeno da corrosão quando exposto a esta temperatura.

A microestrutura do filme formado sobre o aço AISI 409 a $950^{\circ} \mathrm{C}$ apresenta características explícitas de óxido de ferro que é uma camada não protetora (Fig. 4). A oxidação ocorreu em toda sua superfície, com alguns pontos rompidos, de forma que o elemento ferro pode ser identificado como pequenas montanhas pontiagudas sobre o aço. Análises EDS descrevem de forma coerente com a micrografia que o ferro é o elemento químico dominante, sem a presença de outros elementos.

Nas condições de temperatura e pressão em que foram realizados os ensaios, o óxido de cromo é termodinamicamente estável, enquanto o óxido de ferro é instável, de modo que o óxido de cromo deve ser o elemento principal do filme de óxido formado sobre o aço AISI 409, com a função anticorrosivo ${ }^{(10)}$. As análises EDS permitem visualizar esses resultados. É importante relatar que o óxido de cromo não funcionou como um obstáculo à difusão do ferro do substrato, de forma que o aumento da temperatura favoreceu o processo corrosivo do aço.

\section{Análises de fases por difração de Raios X com energia de $8 \mathrm{Kev}$}

O espectro de difração de Raios X para o aço AISI 409 oxidado em ar sintético nas temperaturas de $850^{\circ} \mathrm{C}, 900^{\circ} \mathrm{C}$ e $950^{\circ} \mathrm{C}$ por 2 horas está descrita nas Figs. 5, 6 e 7. Para $850^{\circ} \mathrm{C}$, Fig. 5, as principais fases identificadas foram: óxido de cromo $\left(\mathrm{Cr}_{2} \mathrm{O}_{3}\right)$, trióxido de cromo $\left(\mathrm{CrO}_{3}\right)$ e espinélios do tipo $\left(\mathrm{Fe}_{3} \mathrm{O}_{4}\right)$ e $\mathrm{Cr}_{2} \mathrm{FeO}_{4}$. Apesar da formação do óxido de cromo, o filme gerado sobre o aço não apresenta características protetoras devido a presença marcante do ferro na camada que neste caso, apresenta espessura correspondente a 3,29 $\mu \mathrm{m}$.

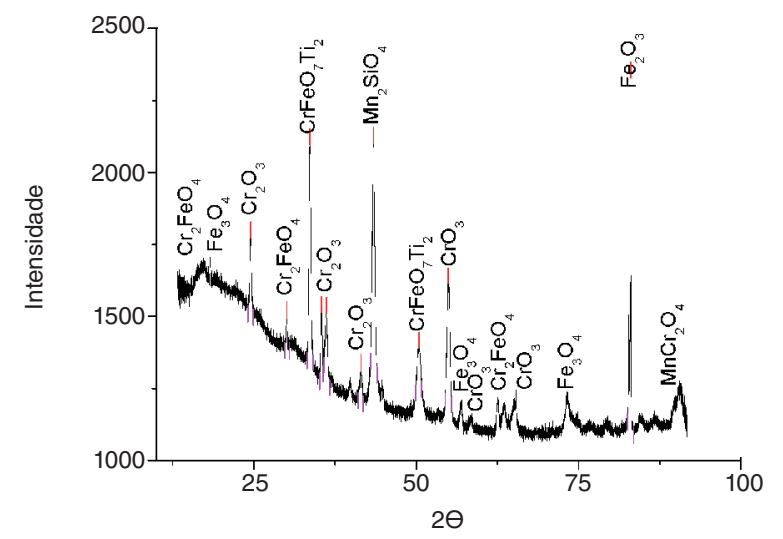

Figura 5: Análise de DRX do filme de óxido formado sobre o aço AISI 409 a $850^{\circ} \mathrm{C}$ oxidado em atmosfera de ar sintético por 2 horas.

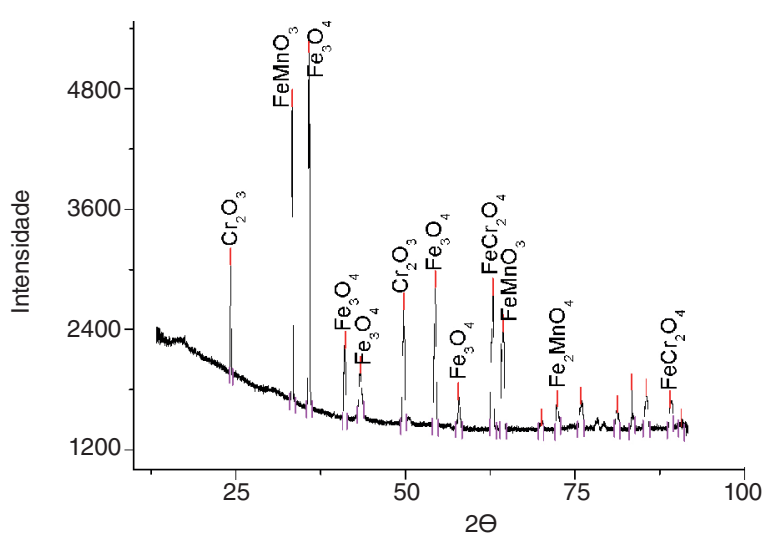

Figura 6 : Análise de DRX do filme de óxido formado sobre o aço AISI 409 a $900^{\circ} \mathrm{C}$ oxidado em atmosfera de ar sintético por 2 horas.

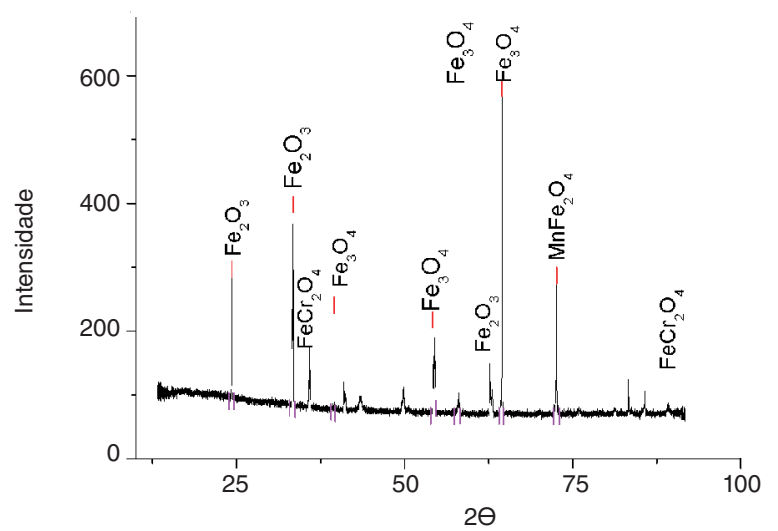

Figura 7: Análise de DRX do filme de óxido formado sobre o aço AISI 409 a $950^{\circ} \mathrm{C}$ oxidado em atmosfera de ar sintético por 2 horas.

Na temperatura de $900^{\circ} \mathrm{C}$ (Fig. 6), a espessura da camada gerada sobre o aço corresponde a 9,17 $\mu \mathrm{m}$ e sua composição apresenta o espinélio $\left(\mathrm{Fe}_{3} \mathrm{O}_{4}\right)$ como a fase majoritária no filme óxido formado sobre o aço 409. O aparecimento do óxido de cromo $\left(\mathrm{Cr}_{2} \mathrm{O}_{3}\right)$ está coerente com a imagem de EDS mostrada na Fig. 3a, que representa uma pequena região baixa da superfície do aço onde ele é gerado.

A Fig. $7\left(950^{\circ} \mathrm{C}\right)$ descreve o DRX da camada de óxido formado sobre o aço 409. Esta camada com espessura de 11,05 $\mu \mathrm{m}$ tem como compostos principais o óxido de ferro $\left(\mathrm{Fe}_{2} \mathrm{O}_{3}\right)$ e espinélio de ferro, $\left(\mathrm{Fe}_{3} \mathrm{O}_{4}\right)$ sendo estes puramente corrosivos. Este resultado concorda com análise EDS da Fig. 4, que apresenta o ferro como elemento principal do filme gerado.

As três figuras apresentadas anteriormente apresentam espessura da camada formada sobre o aço AISI 409, crescente com a temperatura $(3,29 \mu \mathrm{m}, 9,17 \mu \mathrm{m}$ e 11,05 $\mu \mathrm{m})$. Com exceção do primeiro valor, os outros são elevados para representar óxidos protetores. Além do mais, as camadas de espessura 9,17 $\mu \mathrm{m}$ e $11,05 \mu \mathrm{m}$, descamaram com facilidade após a realização da difração de Raios X, não ocorrendo o mesmo fenômeno para a espessura de 3,29 $\mu \mathrm{m}$.

A escamação de óxidos é comum em aços inoxidáveis austeníticos, devido diferença dos coeficientes de dilatação térmica do 
óxido e do substrato, o que leva ao trincamento do óxido, e possibilita que o oxigênio entre em contato com o substrato metáli$\mathrm{Co}^{(11)}$. Este fato é menos evidente nos aços inoxidáveis ferríticos, mas quando o óxido não é protetor a escamação ocorre com mais facilidade, como é ocaso dos óxidos formados a 900 e $950^{\circ} \mathrm{C}$, que são altamente corrosivos.

\section{CONCLUSÕES}

O comportamento de oxidação do aço AISI 409 revelado nos testes entre as temperaturas $850^{\circ} \mathrm{C}$ e $950^{\circ} \mathrm{C}$ descreve uma cinética de oxidação crescente com a temperatura. Sendo que o aço ofereceu maior resistência à oxidação a $850^{\circ} \mathrm{C}$ e menor a $950^{\circ} \mathrm{C}$, durante 2 horas de exposição. As análises EDS mostram que o elemento cromo é majoritário no óxido formado sobre o aço na temperatura de $850^{\circ} \mathrm{C}$, mas com presença de Fe. Para as demais temperaturas predomina o Fe. A DRX dos filmes formados sobre o aço mostrou que seus principais compostos são corrosivos, com exceção do $\mathrm{Cr}_{2} \mathrm{O}_{3}$. De forma que pode-se descrever que as camadas de óxidos geradas sobre o aço AISI 409 nas três temperaturas não são protetoras.

\section{AGRADECIMENTOS}

Os autores agradecem ao IFPI, UEMA, FAPEMA e ArcellorMittal.

\section{REFERÊNCIAS}

1. PARDINI, A.C.P., Estudo da oxidação em altas temperaturas dos aços inoxidáveis AISI 430A e AISI 430E. Dissertação de Mestrado (2008). REDEMAT, Universidade Federal de Ouro Preto, Ouro Preto (MG).

2. SABIONI, A.C.S.; HUNTZ, A.M.; SALGADO, M.F.; PARDINI, A.C.P; ROSSI, E.H.; PANIAGO, R.M.; AND V. Ji., Materials at high Temperatures 27(2) (2010) 89-96.

3. ACCHAR, W.; BARRETO, L.S.; JUNIOR, H.R.P.; CRUZ, C.R.; FEISTAUER, E.E., Materials Research 15(6) (2012) 1064-1069.

4. LAVERDE, D.; ACEBO,T.G.; CASTRO, F., Corrosion science 46 (2004) 613-631.

5. SALGADO, M.F.; SABIONI, A. C. S.; HUNTZ, A.M.; ROSSI, E. H., Materials Research 11(2) (2008) 227-232.

6. NIEKERK, C.J.V. and TOIT, D.M., The journal of the Southen Africa 111(2011) 243-255

7. GORDON, W.; BENNEKOM, A.V., Materials science and Tecnology 12(2) (1996) 126-131

8. VAZQUEZ, A; VARMA, S.K., Journal of Alloys and Compounds 509 (2011) 7027-7033.

9. EBRAHIMIFAR, H; ZANDRAHIMI, M., Surface \& Coatings Technology 206 (2011) 75-81.

10. HUNTZ, A.M.; RECKMANN, A.; HAUT, C.; SÉVÉRAC, C.; HERBST, M.; RESENDE, F.C.T.; SABIONI, A.C.S., Materials Science and Engineering, 447 (2011) 266-276.

11 FARIA, R. A., Efeito dos elementos Ti e Nb no comportamento em fadiga de aços inoxidáveis ferríticos utilizados no sistema de exaustão de veículos automotores. Dissertação de mestrado (2006). Universidade Federal de Ouro Preto, Ouro Preto, (MG). 